\title{
Emergency department use in people who experience imprisonment in Ontario, Canada
}

\author{
John Tuinema, MD*; Aaron M. Orkin, MD, MSc, MPH ${ }^{\dagger \neq}$; Stephanie Y. Cheng, MSc ${ }^{\varsigma}$; \\ Kinwah Fung, $\mathrm{MSc}^{\S}$; Fiona G. Kouyoumdjian, $\mathrm{MD}, \mathrm{MPH}, \mathrm{PhD}^{\S \boldsymbol{I}^{* *}}$
}

\begin{abstract}
CLINICIAN'S CAPSULE
What is known about the topic?

People who experience imprisonment have poor health status compared with the general population, and limited US data indicate high ED utilization.

What did this study ask?

What are the rates and acuity of ED utilization for men and women in Ontario in prison and after release?

What did this study find?

In prison and post-release, men and women had higher ED utilization rates than age- and sex-matched people, mostly for high-acuity conditions.

Why does this study matter to clinicians?

Providing excellent ED care and delivering interventions in prison and in the ED could improve health for this population.
\end{abstract}

\section{ABSTRACT}

Objectives: The aims of this study were to describe emergency department (ED) utilization by people in provincial prison and on release, and to compare with ED utilization for the general population.

Methods: We linked correctional and health administrative data for people released from provincial prison in Ontario in 2010. We matched each person by age and sex with four people in the general population. We compared ED utilization rates using generalized estimating equations, by sex and for high urgency and ambulatory care sensitive conditions.

Results: People who experienced imprisonment $(N=48,861)$ had higher ED utilization rates compared with the general population $(\mathrm{N}=195,444)$, with rate ratios of $3.2(95 \% \mathrm{Cl} 3.0-4.4)$ for men and $6.5(95 \% \mathrm{Cl} 5.6-7.5)$ for women in prison and a range of rate ratios between 3.1 and 7.7 for men and 4.2 and 8.8 for women over the 2 years after release. Most ED visits were high urgency, and between $1.0 \%$ and $5.1 \%$ of visits were for ambulatory care sensitive conditions. ED utilization rates increased on release from prison.

Conclusions: People experiencing imprisonment in Ontario have higher ED utilization compared with matched people in the general population, primarily for urgent issues, and particularly in women and in the week after release. Providing high-quality ED care and implementing prison- and EDbased interventions could improve health for this population and prevent the need for ED use.

\section{RÉSUMÉ}

Objectifs: L'étude visait à décrire l'utilisation des services des urgences (SU) par les personnes incarcérées dans des prisons provinciales et par celles en ayant été libérées, et à comparer I'utilisation des SU par la population incarcérée avec celle qu'en fait la population générale.

Méthode: Des données administratives provenant des services correctionnels ont été liées à des données administratives sur la santé des personnes libérées de prisons provinciales, en Ontario, en 2010. L'équipe de recherche a ensuite procédé à l'appariement, selon l'âge et le sexe, de chaque personne visée avec quatre personnes provenant de la population générale. Enfin, il y a eu comparaison des taux d'utilisation des SU à l'aide d'équations d'estimation généralisée, selon le sexe et selon la gravité des troubles nécessitant soit des soins très urgents, soit des soins ambulatoires.

Résultats: Les personnes ayant séjourné en prison ( $n=48861)$ ont connu des taux plus élevés d'utilisation des $\mathrm{SU}$ que les personnes appariées provenant de la population générale $(n=195$ 444); en effet, des ratios de taux de 3,2 (IC à $95 \%: 3,0-4,4$ ) ont été enregistrés pour les hommes en prison et de 6,5 (IC à $95 \%$ : $5,6-7,5)$ pour les femmes en prison, et des plages de ratios de taux variant de 3,1 à 7,7 pour les hommes et de 4,2 à 8,8 pour les femmes ont été enregistrées sur la période de 2 ans suivant la libération de prison. La plupart des consultations au SU étaient justifiées par des troubles nécessitant des soins très urgents, et de $1,0 \%$ à 5,1 \% des consultations, par des troubles

From the *Northern Ontario School of Medicine, Sudbury, ON; †Department of Family and Community Medicine, University of Toronto, ON; $\neq$ Dalla Lana School of Public Health, University of Toronto, ON; §Institute for Clinical Evaluative Sciences, Toronto, ON; IDepartment of Family Medicine, McMaster University, Hamilton, ON; and ${ }^{*}$ Centre for Urban Health Solutions, St. Michael's Hospital, Toronto, ON.

Correspondence to: Dr. Fiona Kouyoumdjian, David Braley Health Sciences Centre, 5th floor, 100 Main Street West, Hamilton, ON L8P 1H6; Email: kouyouf@mcmaster.ca

(c) Canadian Association of Emergency Physicians

CJEM 2020;22(2):232-240

DOI 10.1017/cem.2019.401 
nécessitant des soins ambulatoires. Les taux d'utilisation des SU augmentaient après la libération de prison.

Conclusions: Les personnes incarcérées en Ontario ont un taux d'utilisation des SU plus élevé que les personnes appariées provenant de la population générale, et ce, pour des troubles principalement urgents, notamment chez les femmes et au cours de la semaine suivant la libération. La prestation de soins de qualité au SU et la mise en œuvre d'interventions en prison et au SU pourraient améliorer la santé de la population incarcérée et ainsi prévenir la nécessité de consulter au SU.

Keywords: Health services, medicine and the law, public health

\section{INTRODUCTION}

Internationally, people who experience imprisonment have worse health status than the general population. ${ }^{1,2}$ In Canada, where over 37,000 people are in prison at any given time, ${ }^{3}$ there is a paucity of data on access to healthcare ${ }^{4}$ and on the specific challenges of providing effective emergency department (ED) care for this population.

U.S. studies have shown that a history of imprisonment is associated with increased ED utilization in prison and after prison release. A Rhode Island study showed that people released from prison had more ED visits compared with the general population, mostly due to mental health concerns, substance use disorders, and ambulatory care sensitive conditions, ${ }^{5}$ which are medical conditions for which ambulatory care should prevent or reduce hospital use. ${ }^{6}$ A longitudinal study of older adults in California identified high ED utilization rates in prison and post-release. ${ }^{7}$ A study of persons with human immunodeficiency virus (HIV) at the time of release from prison in Connecticut found increased ED utilization that was driven largely by comorbid medical and psychiatric conditions. ${ }^{8}$ Another California study found that most ED utilization for people who experienced imprisonment was for mental health conditions, and this population had a higher proportion of frequent ED use than the general population. ${ }^{9}$ Research on ED use in people who experience imprisonment is limited, however, by a focus on subpopulations, ${ }^{7-9}$ examination of only the post-release period, ${ }^{5,8}$ and having been conducted only in the United States, in which there is a lack of universal health insurance. ${ }^{5,7-9}$

Population-based data on ED utilization could offer valuable insights regarding the health status, healthcare needs, and access to care for this structurally vulnerable population. Building on initial research on healthcare utilization for this population across settings, ${ }^{10}$ our objective was to describe the ED utilization of men and women in prison and after release, and to compare these data with data for the general population in Ontario, Canada. We explored ED utilization for high urgency and ambulatory care sensitive conditions.

\section{METHODS}

\section{Study design and setting}

We conducted a cohort study of people released from provincial prison in Ontario, Canada, in 2010 and ageand sex-matched people from the general population. Provincial correctional facilities in Canada hold people who are awaiting trial or sentencing, or who are sentenced to less than 2 years in prison. ${ }^{11}$

In Ontario, provincial prisons are publicly funded and administered. For Ontario residents, hospitalizations and medically necessary physician services are paid for through the public health insurance system, the Ontario Health Insurance Plan (OHIP), including in provincial prison.

\section{Participants}

For all adults released from provincial prison in Ontario in 2010, the Ontario Ministry of Community Safety and Correctional Services transferred data to ICES, an independent, non-profit organization funded by the Ontario Ministry of Health and Long-Term Care, which holds health administrative data for Ontario residents. As described previously, ${ }^{10}$ we linked these data with an encoded OHIP number in the Registered Persons Database, which is a database of people who are eligible for OHIP coverage. We linked using OHIP numbers when provided and valid, and otherwise with a validated deterministic or probabilistic linkage method using 
name and date of birth. ${ }^{12}$ We excluded apparently incorrect linkages and people not released to the community (Appendix).

For each person in the prison release group, we randomly selected four age- and sex-matched people from the Registered Persons Database who were registered for OHIP coverage on the date of release for the person released from prison. We matched for age and sex because these factors are strongly associated with healthcare utilization. ${ }^{13,14}$ We used a matching ratio of $4: 1$ for statistical efficiency. ${ }^{15}$

\section{Measurements}

\section{Sociodemographic information}

We defined neighbourhood income quintile and rural/ small town residence using the postal code at the time of prison release. From correctional data, we used the self-reported race categories, Aboriginal, Black, and White, and we combined remaining categories and missing people into a Missing/Other category.

\section{Morbidity}

Using methods validated using ICES data, ${ }^{16-21}$ we identified people with a diagnosis of diabetes, hypertension, chronic obstructive pulmonary disease (COPD), asthma, congestive heart failure (CHF), and HIV. We applied definitions from the Ontario Mental Health and Addictions Scorecard and Evaluation Framework to identify people with a diagnosis in the past 2 years of any substance-related disorders, anxiety disorders, mood disorders, or schizophrenia. ${ }^{22}$ To describe morbidity burden, we used the Johns Hopkins Adjusted Clinical Group system, ${ }^{23}$ based on diagnostic codes in OHIP for ambulatory care, the Canadian Institute for Health Information (CIHI) Discharge Abstract Database for hospitalizations, and the Same Day Surgery Database. For each person, we calculated the number of Aggregated Diagnosis Groups, which are 32 diagnosis clusters that indicate the burden of disease morbidity, ${ }^{24}$ using data for the 2 years prior to the initial release from provincial prison in 2010 or the corresponding date for matched people in the general population.

\section{Outcomes}

We used CIHI National Ambulatory Care Reporting System data for ED visits. We excluded planned or scheduled visits. We categorized ED visits as high urgency if the Canadian Triage Acuity Scale (CTAS) was 1 (resuscitation), 2 (emergent), or 3 (urgent), or if the patient was admitted to hospital, as done previously. ${ }^{25,26}$ To identify ambulatory care sensitive conditions, we applied International Classification of Disease (ICD) codes for seizures, COPD, asthma, heart failure and pulmonary edema, hypertension, angina, and diabetes. ${ }^{6,27}$ Using the main diagnosis in National Ambulatory Care Reporting System data, we categorized ED visit reasons by ICD10-CA chapter. ${ }^{28}$

\section{Analysis}

We described characteristics of those in the prison release group and the general population.

We ended the follow-up period at the earliest of death, loss of OHIP eligibility, prison re-admission (for the prison release group), or 2 years post-release (or the corresponding date for the general population group). We calculated person-time as the number of days in each period under study. We calculated the ED utilization rate as the number of ED encounters divided by persontime at risk, and by period relative to the time in prison, that is, in prison during the admission prior to the initial release in 2010 and by period after the initial release in 2010. For each person in the general population, we used the admission and release dates for the matched person in the prison group. For example, if a person was admitted to prison on January 1, 2010, and released on February 1, 2010, we used those dates for those matched to that person as the time "in prison" and February 1,2010 , as the date of release. We considered rates as statistically significantly different if their $95 \%$ CIs did not overlap. ${ }^{29}$

We calculated rate ratios for ED utilization for the prison release group compared with the general population group. We used generalized estimating equations with a negative binomial model, in which we controlled for correlation due to matching. For each sex, we developed bivariate models to describe the unadjusted association between imprisonment status and ED utilization, and multivariable models adjusted for neighbourhood income quintile and rurality, to see if associations persisted after controlling for these potential confounders. We calculated rates of ED utilization overall, for high urgency visits, and for ambulatory care sensitive conditions.

We calculated the proportion of people in the prison release group and general population group who 


\begin{tabular}{|c|c|c|c|}
\hline Characteristic & & $\begin{array}{l}\text { Prison release group, } \\
\qquad N=48,861\end{array}$ & $\begin{array}{l}\text { General population group, } \\
\qquad N=195,444\end{array}$ \\
\hline Age & Median (IQR) years & $32(24-43)$ & $32(24-43)$ \\
\hline \multirow[t]{2}{*}{ Sex } & Male & $87.5 \%$ & $87.5 \%$ \\
\hline & Female & $12.5 \%$ & $12.5 \%$ \\
\hline \multirow[t]{4}{*}{ Self-reported race* } & Missing/other & $19.6 \%$ & - \\
\hline & White & $58.8 \%$ & - \\
\hline & Black & $11.4 \%$ & - \\
\hline & Aboriginal & $10.1 \%$ & - \\
\hline \multirow[t]{6}{*}{ Neighbourhood income quintile } & Missing & $4.7 \%$ & $0.5 \%$ \\
\hline & 1 (lowest) & $37.1 \%$ & $20.0 \%$ \\
\hline & 2 & $21.5 \%$ & $20.0 \%$ \\
\hline & 3 & $15.8 \%$ & $20.0 \%$ \\
\hline & 4 & $12.1 \%$ & $20.5 \%$ \\
\hline & 5 & $8.8 \%$ & $19.0 \%$ \\
\hline Rural/small town & Yes & $13.0 \%$ & $10.6 \%$ \\
\hline \multirow[t]{2}{*}{ Time in provincial prison, median (IQR) days } & Admission leading to initial 2010 release & $10(3-52)$ & - \\
\hline & Past 5 years & $72(12-230)$ & - \\
\hline \multirow[t]{3}{*}{ Number of aggregated diagnosis groups } & $0-4$ & $51.9 \%$ & $69.8 \%$ \\
\hline & $5-9$ & $35.6 \%$ & $26.5 \%$ \\
\hline & $\geq 10$ & $12.4 \%$ & $3.7 \%$ \\
\hline \multirow[t]{6}{*}{ Chronic disease prevalence $^{\dagger}$} & Diabetes & $4.8 \%$ & $4.1 \%$ \\
\hline & Hypertension & $7.4 \%$ & $8.7 \%$ \\
\hline & COPD & $4.5 \%$ & $2.0 \%$ \\
\hline & Asthma & $16.4 \%$ & $13.8 \%$ \\
\hline & $\mathrm{CHF}$ & $0.3 \%$ & $0.3 \%$ \\
\hline & HIV & $0.7 \%$ & $0.2 \%$ \\
\hline \multirow[t]{4}{*}{ Mental health disorders prevalence ${ }^{\dagger}$} & Mood disorders & $6.8 \%$ & $0.8 \%$ \\
\hline & Schizophrenia & $3.9 \%$ & $0.4 \%$ \\
\hline & Anxiety disorders & $7.7 \%$ & $1.2 \%$ \\
\hline & Substance-related disorders & $16.9 \%$ & $1.2 \%$ \\
\hline
\end{tabular}

accessed ED care in each follow-up period, including high urgency visits and the number and proportion of visits in each follow-up period by reason for use.

We obtained study approval from the St. Michael's Hospital Research Ethics Board (study 15-296) and from the Hamilton Integrated Research Ethics Board (study 4422-C).

\section{RESULTS}

\section{Characteristics of study participants}

Of 53,955 people released from provincial prison in Ontario in 2010, we achieved valid linkage for
52,546 (97.4\%) (Appendix). We excluded 3,685 people who were not released to the community in 2010. We matched the 48,861 people in the prison release group with 195,444 people in the general population. By the end of the 2-year follow-up period, 673 people $(1.4 \%)$ in the prison release group and 581 people $(0.3 \%)$ in the general population group had died.

Compared with the general population group, people in the prison release group were more likely to live in neighbourhoods with the lowest income quintile, to have a higher number of aggregated diagnosis groups, to have COPD, and to have a mood disorder, schizophrenia, an anxiety disorder, or a substance-related disorder (Table 1). 


\begin{tabular}{|c|c|c|c|c|c|c|c|}
\hline \multirow[b]{2}{*}{$\begin{array}{l}\text { Period relative to } \\
\text { time in prison* }\end{array}$} & & \multicolumn{3}{|c|}{ Men } & \multicolumn{3}{|c|}{ Women } \\
\hline & & $\begin{array}{c}\text { Crude rate (visits/ } \\
\text { person-year) }(95 \% \text { Cl) }\end{array}$ & $\begin{array}{l}\% \text { Visits high } \\
\text { urgency }^{\dagger}\end{array}$ & $\begin{array}{l}\% \text { Visits } \\
\text { for ACSC }\end{array}$ & $\begin{array}{c}\text { Crude rate (visits/ } \\
\text { person-year) }(95 \% \mathrm{Cl})\end{array}$ & $\begin{array}{l}\% \text { Visits high }^{\text {urgency }^{\dagger}}\end{array}$ & $\begin{array}{l}\% \text { Visits } \\
\text { for ACSC }\end{array}$ \\
\hline In prison & & $0.6(0.6,0.6)$ & $64.2 \%$ & $3.2 \%$ & $1.3(1.2,1.4)$ & $73.0 \%$ & $5.1 \%$ \\
\hline \multirow[t]{6}{*}{ Post-release (days) } & $0-6$ & $2.5(2.4,2.7)$ & $59.0 \%$ & $2.0 \%$ & $3.3(3.0,3.6)$ & $65.2 \%$ & $1.0 \%$ \\
\hline & $7-29$ & $1.6(1.5,1.6)$ & $56.4 \%$ & $2.2 \%$ & $2.5(2.4,2.7)$ & $62.1 \%$ & $1.1 \%$ \\
\hline & $30-89$ & $1.3(1.3,1.3)$ & $56.6 \%$ & $2.2 \%$ & $2.3(2.2,2.4)$ & $60.2 \%$ & $2.2 \%$ \\
\hline & $90-179$ & $1.2(1.1,1.2)$ & $56.0 \%$ & $2.1 \%$ & $2.1(2.0,2.2)$ & $61.5 \%$ & $1.9 \%$ \\
\hline & $180-364$ & $1.1(1.0,1.1)$ & $57.8 \%$ & $2.3 \%$ & $1.9(1.8,2.0)$ & $63.6 \%$ & $1.9 \%$ \\
\hline & $365-730$ & $1.0(1.0,1.0)$ & $59.3 \%$ & $2.5 \%$ & $1.7(1.7,1.8)$ & $63.5 \%$ & $2.6 \%$ \\
\hline
\end{tabular}

\section{ED utilization in prison}

In prison, men used the ED 0.6 times per person-year and women used the ED 1.3 times per person-year (Table 2), and $6.6 \%$ of people in the prison release group used the ED (Appendix). For men, $64.2 \%$ of visits were high urgency, and $73.0 \%$ of visits were high urgency for women. Ambulatory care sensitive conditions accounted for $3.2 \%$ of $\mathrm{ED}$ visits for men and $5.1 \%$ for women. By ICD-10-CA chapter, the main diagnosis was injury, poisoning, and certain other consequences of external causes for $34.7 \%$ of visits, symptoms, signs, and abnormal clinical and laboratory findings not otherwise classified for $17.4 \%$ of visits, and mental and behavioural disorders for $11.9 \%$ of visits (Table 3 ).

Compared with the general population in the corresponding time period, rates of use and the proportion of people with ED use were higher for men and women while in prison (Table 4, Figure 1, and Appendix). Rate ratios did not change substantially after adjusting for neighbourhood income quintile and rurality, at 3.2 for men and 6.4 for women (see Table 4).

\section{ED utilization post-release}

For the prison release group in the week after release, the ED utilization rate increased compared with the rate in prison (see Table 2) and 4.0\% of people accessed ED care (Appendix). Over the 2 years post-release, the ED utilization rate decreased, and the majority of visits were high urgency (see Table 2). Ambulatory care sensitive conditions accounted for $1.0 \%$ to $2.6 \%$ of visits for men and women over the 2-year period (see Table 2).
By ICD-10-CA chapter, the main reasons for ED use in the 2 years post-release were similar to those in prison, with $23.6 \%$ for injury, poisoning and certain other consequences of external causes, $17.2 \%$ for mental and behavioural disorders, $15.5 \%$ for symptoms, signs and abnormal clinical and laboratory findings not elsewhere classified, and $10.7 \%$ for factors influencing health status and contact with health services (see Table 3).

During all periods post-release, the overall and high urgency ED utilization rates were significantly increased for men and women in the prison release group compared with the general population (see Table 4 and Figure 1), and a higher proportion of people in the prison release group accessed care compared with the general population group (Appendix).

\section{ED utilization by women who experienced imprisonment}

In prison and post-release, the ED utilization rate was significantly higher for women than men in the prison release group, and over $60 \%$ of visits were high urgency (see Table 2). For women, ED visits for ambulatory care sensitive conditions made up $5.1 \%$ of visits while in prison and $1.0 \%$ of ED visits during the week after release.

\section{DISCUSSION}

We found that rates of ED utilization were markedly higher for people in prison and after release compared with age- and sex-matched people in the general population. Rates of ED utilization were highest in the week 


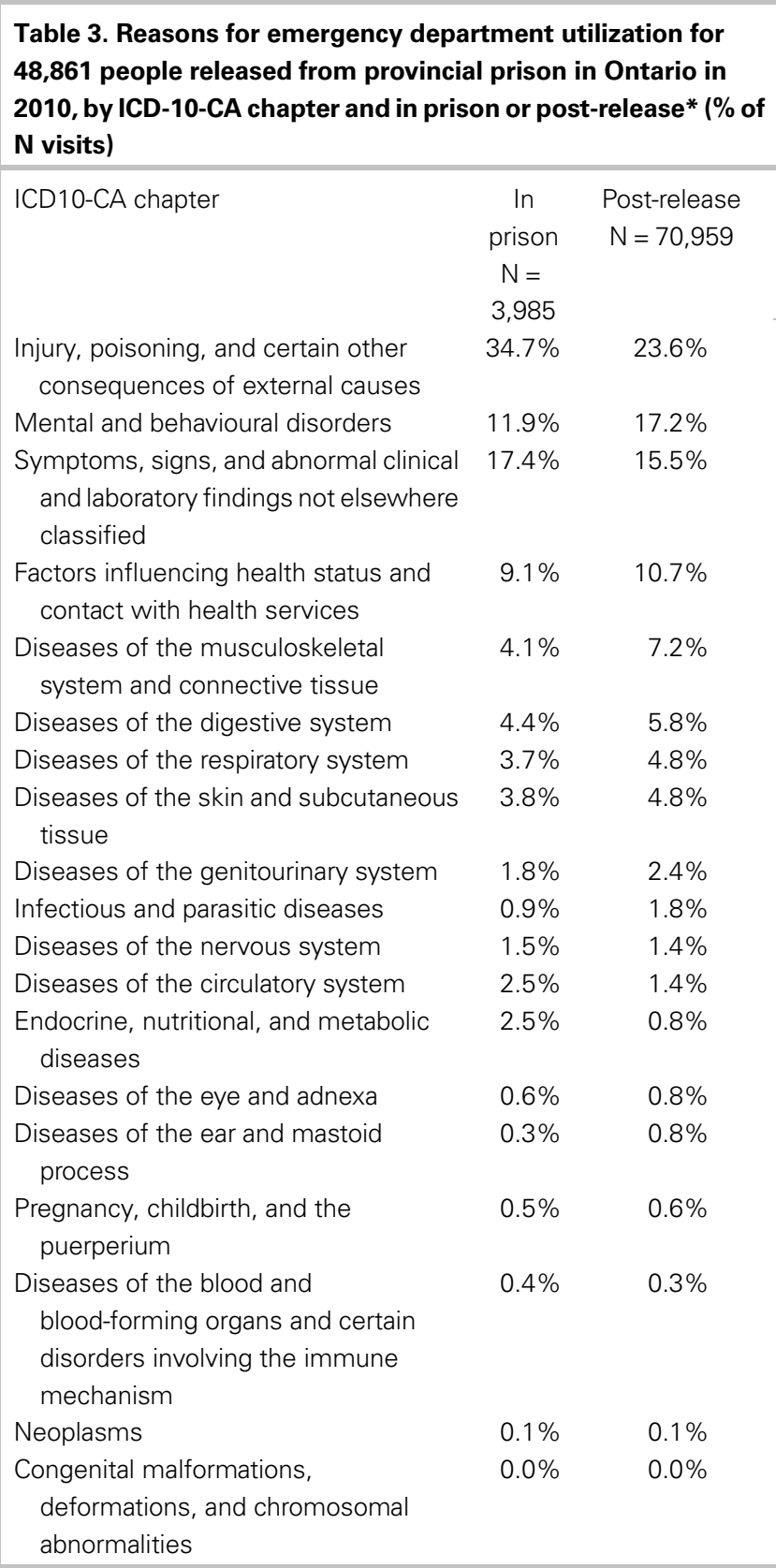

* In prison refers to the time in prison during the admission prior to the initial release in 2010, and post-release refers to the 2 years after the initial release in 2010.

after prison release. The majority of ED visits were high urgency, and a small proportion of visits were for ambulatory care sensitive conditions. The most common reasons for ED visits were related to injury and mental health disorders. In the prison-release group, women had significantly higher ED utilization than men and had a large proportion of high urgency visits.
Strengths of this study include that we comprehensively assessed ED utilization in prison and on release for a large and population-based sample, including for high urgency visits and for ambulatory care sensitive conditions. Instead of relying on self-reported healthcare use, we accessed health administrative data, which are comprehensive for Ontario residents in the setting of universal healthcare. We compared rates of use with several age- and sex-matched people in the general population for each person in the prison-release group.

This study also has several limitations. Indigenous people are overrepresented in provincial prisons, and healthcare utilization on First Nations is not included in provincial health administrative data. Healthcare utilization rates post-release may therefore underestimate use, which would lead to a conservative bias. Reasons for ED use are provided only by ICD-10-CA chapter, each of which includes multiple conditions or diseases. Our main study objective was to describe ED utilization in people who experience imprisonment, and we did not develop explanatory models to understand the causal impact of imprisonment on ED utilization. In prison, healthcare providers and correctional staff decide whether to send a patient to the ED, which could lead to fewer visits and proportionately greater use for high urgency reasons. The study results may not be generalizable to other jurisdictions, for example, those with different healthcare systems.

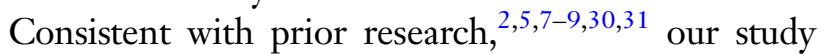
demonstrates that people who experience imprisonment are high users of EDs in comparison with the general population, and that a high proportion of visits was for injury and mental health issues. The majority of ED visits were for acute problems that were not ambulatorycare sensitive, suggesting that these patients may be using the ED more because they need the ED more for high-acuity care. For this population, therefore, efforts should focus on reducing the risk of emergency health issues, rather than on reducing unnecessary ED visits, recognizing that the same interventions such as discharge planning, case management, and primary care referral may be effective at achieving either goal. ${ }^{32,33}$

This study has implications for ED care and research. Given the high ED use rate for people who experience imprisonment, ED clinicians and administrators might work towards ensuring appropriate and nondiscriminatory care in the ED for people in custody, ${ }^{34-37}$ supporting effective transitions of care to and from prison, and developing mechanisms to identify patients who were 


\begin{tabular}{|c|c|c|c|c|c|}
\hline \multirow[b]{2}{*}{$\begin{array}{l}\text { Period relative to } \\
\text { time in prison* }\end{array}$} & & \multicolumn{2}{|c|}{ Rate ratio for men } & \multicolumn{2}{|c|}{ Rate ratio for women } \\
\hline & & $\begin{array}{c}\text { Unadjusted } \\
(95 \% \mathrm{Cl})\end{array}$ & $\begin{array}{l}\text { Adjusted for income } \\
\text { and rurality } \\
(95 \% \mathrm{Cl})\end{array}$ & $\begin{array}{l}\text { Unadjusted } \\
(95 \% \mathrm{Cl})\end{array}$ & $\begin{array}{l}\text { Adjusted for income } \\
\text { and rurality } \\
(95 \% \mathrm{Cl})\end{array}$ \\
\hline In prison & & $3.2(3.0,3.4)$ & $3.2(3.0,3.3)$ & $6.5(5.6,7.5)$ & $6.4(5.5,7.6)$ \\
\hline \multirow[t]{6}{*}{ Post-release (days) } & $0-6$ & $7.7(7.1,8.4)$ & $7.8(7.1,8.5)$ & $8.8(7.2,10.8)$ & $8.5(6.9,10.6)$ \\
\hline & $7-29$ & $4.8(4.6,5.2)$ & $4.9(4.6,5.2)$ & $6.4(5.6,7.3)$ & $6.3(5.5,7.3)$ \\
\hline & $30-89$ & $4.1(3.9,4.3)$ & $4.0(3.8,4.2)$ & $6.1(5.5,6.8)$ & $6.0(5.4,6.7)$ \\
\hline & $90-179$ & $3.6(3.5,3.8)$ & $3.6(3.4,3.7)$ & $5.5(4.9,6.0)$ & $5.3(4.8,5.9)$ \\
\hline & $180-364$ & $3.3(3.2,3.5)$ & $3.3(3.1,3.4)$ & $4.8(4.4,5.3)$ & $4.8(4.3,5.2)$ \\
\hline & $365-730$ & $3.1(2.9,3.2)$ & $2.9(2.8,3.1)$ & $4.2(3.9,4.6)$ & $4.0(3.6,4.5)$ \\
\hline
\end{tabular}

* In prison refers to the time in prison during the admission prior to the initial release in 2010 , and post-release refers to the time after the initial release in 2010 or the corresponding period for matched people in the general population.

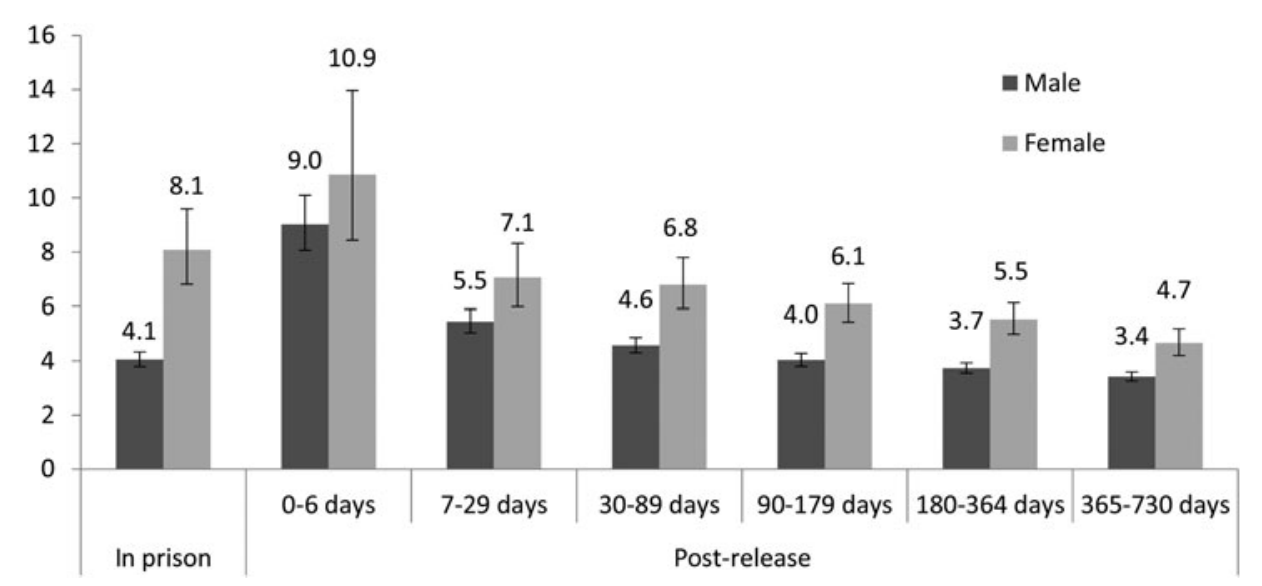

Figure 1. Rate ratios of high urgency* emergency department utilization for people released from provincial prison in Ontario in 2010 compared with age- and sex-matched people in the general population, by the period relative to time in prison ${ }^{\dagger}$ and gender. * High urgency includes visits with a Canadian Triage Acuity Scale (CTAS) of 1 (resuscitation), 2 (emergent), or 3 (urgent) or if the patient was admitted to hospital. ${ }^{\dagger}$ In prison refers to the time in prison during the admission prior to the initial release in 2010 , and post-release refers to the time after the initial release in 2010, or the corresponding period for matched people in the general population.

recently released from prison and facilitating access to primary care. To better define prevention opportunities and treatment needs, future research should focus on the pathways leading to ED use for this population, including from the patient perspective, as well as on implementing and evaluating ED- and community-based strategies to reduce the risk of emergency health issues.

\section{CONCLUSION}

In conclusion, people who experience imprisonment have a high rate of ED utilization in prison and after prison release. Improved prison discharge planning, connecting patients who experience imprisonment with appropriate services, and attention to the health of women experiencing imprisonment are important foci, particularly at the time of prison release.

Acknowledgements: This study was supported by ICES, which is funded by an annual grant from the Ontario Ministry of Health and Long-Term Care (MOHLTC). We acknowledge the Ontario Ministry of Community Safety and Correctional Services (MCSCS), which supported the study, and we appreciate the contributions of Mr. Michael Kirk to the study.

Parts of this material are based on data and/or information compiled and provided by CIHI. However, the analyses, conclusions, opinions, and statements expressed in the material are those of the authors and not necessarily those of CIHI. The analyses, opinions, results, and conclusions reported in this paper are also independent from the other sources that provided data and 
funding. No endorsement by ICES, the MOHLTC, or the MCSCS is intended or should be inferred.

Financial support: This study was funded by grants from the Physicians' Services Incorporated Foundation (15-22) and the Foundation for Advancing Family Medicine of the College of Family Physicians of Canada.

Competing interests: None declared.

\section{SUPPLEMENTARY MATERIAL}

The supplementary material for this article can be found at https://doi.org/10.1017/cem.2019.401

\section{REFERENCES}

1. Fazel S, Baillargeon J. The health of prisoners. Lancet 2011;377(9769):956-65.

2. Kouyoumdjian F, Schuler A, Matheson FI, et al. The health status of prisoners in Canada: a narrative review. Can Fam Physician 2016;62(3):215-22.

3. Walmsley R. World prison population list, 11th edition. London, UK: King's College London International Centre for Prison Studies; 2016.

4. Kouyoumdjian FG, Schuler A, Hwang SW, et al. Research on the health of people who experience detention or incarceration in Canada: a scoping review. BMC Public Health 2015;15:419.

5. Frank JW, Andrews CM, Green TC, et al. Emergency department utilization among recently released prisoners: a retrospective cohort study. BMC Emerg Med 2013;13:16.

6. Canadian Institutes for Health Research. CIHI Health Indicator Library: ambulatory care sensitive conditions; updated 2018. Available at: http://indicatorlibrary.cihi.ca/display/ HSPIL/Ambulatory+Care+Sensitive+Conditions (accessed June 28, 2018).

7. Humphreys J, Ahalt C, Stijacic-Cenzer I, et al. Six-month emergency department use among older adults following jail incarceration. 7 Urban Health 2018;95(4):523-33.

8. Meyer JP, Qiu J, Chen NE, et al. Frequent emergency department use among released prisoners with human immunodeficiency virus: characterization including a novel multimorbidity index. Acad Emerg Med 2013;20(1):79-88.

9. McConville S, Mooney AC, Williams BA, et al. How do ED patients with criminal justice contact compare with other ED users? A retrospective analysis of ED visits in California. BMF Open 2018;8:epub.

10. Kouyoumdjian FG, Cheng SY, Fung K, et al. The health care utilization of people in prison and after prison release: a population-based cohort study in Ontario, Canada. PLoS One 2018;13(8):epub.

11. Reitano J. Adult correctional statistics in Canada, 2015/2016; 2017. Available at: http://www.statcan.gc.ca/pub/85-002-x/ 2017001/article/14700-eng.htm (accessed June 28, 2018).
12. Chong N, ed. IARC Technical Reports No. 32: automated data collection in cancer registration: computerized record linkage in cancer registries. International Agency for Research on Cancer. Lyon, France: World Health Organization; 1998.

13. Blackwell DL, Martinez ME, Gentleman JF, et al. Socioeconomic status and utilization of health care services in Canada and the United States: findings from a binational health survey. Med Care 2009;47(11):1136-46.

14. Fitzpatrick T, Rosella LC, Calzavara A, et al. Looking beyond income and education: socioeconomic status gradients among future high-cost users of health care. Am 7 Prev Med 2015; epub.

15. Morgenstern H, Winn DM. A method for determining the sampling ratio in epidemiologic studies. Stat Med 1983;2 (3):387-96.

16. Antoniou T, Zagorski B, Loutfy MR, et al. Validation of casefinding algorithms derived from administrative data for identifying adults living with human immunodeficiency virus infection. PLoS One 2011;6(6):e21748.

17. Gershon AS, Wang C, Guan J, et al. Identifying patients with physician-diagnosed asthma in health administrative databases. Can Respir 7 2009;16(6):183-8.

18. Gershon AS, Wang C, Guan J, et al. Identifying individuals with physician diagnosed COPD in health administrative databases. COPD 2009;6(5):388-94.

19. Hux JE, Ivis F, Flintoft V, et al. Diabetes in Ontario: determination of prevalence and incidence using a validated administrative data algorithm. Diabetes Care 2002;25(3):512-6.

20. Schultz SE, Rothwell DM, Chen Z, et al. Identifying cases of congestive heart failure from administrative data: a validation study using primary care patient records. Chronic Dis Inj Can 2013;33(3):160-6.

21. Tu K, Campbell NR, Chen ZL, et al. Accuracy of administrative databases in identifying patients with hypertension. Open Med 2007;1(1):e18-26.

22. MHASEF Research Team. Mental health and addictions system performance in Ontario: a baseline scorecard. Toronto (ON): Institute for Clinical Evaluative Sciences; 2018.

23. ACG Johns Hopkins. The Johns Hopkins ACG system; 2018. Available at: https://www.hopkinsacg.org/ (accessed February 22, 2018).

24. Austin PC, van Walraven C, Wodchis WP, et al. Using the Johns Hopkins Aggregated Diagnosis Groups (ADGs) to predict mortality in a general adult population cohort in Ontario, Canada. Med Care 2011;49(10):932-9.

25. Khan Y, Glazier RH, Moineddin R, et al. A population-based study of the association between socioeconomic status and emergency department utilization in Ontario, Canada. Acad Emerg Med 2011;18(8):836-43.

26. Murray M, Bullard M, Grafstein E, et al. Revisions to the Canadian Emergency Department Triage and Acuity Scale implementation guidelines. CFEM 2004;6(6):421-7.

27. Billings J, Zeitel L, Lukomnik J, et al. Impact of socioeconomic status on hospital use in New York City. Health Aff 1993;12(1):162-73.

28. Canadian Institute for Health Information. ICD-10-CA chapters; 2019. Available at: https://www.cihi.ca/en/icd-10ca-chapters (accessed May 9, 2019). 
29. Knezevic A. Overlapping confidence intervals and statistical significance: Cornell University; 2008. Available at: https:// www.cscu.cornell.edu/news/statnews/stnews73.pdf (accessed March 29, 2019).

30. Frank JW, Linder JA, Becker WC, et al. Increased hospital and emergency department utilization by individuals with recent criminal justice involvement: results of a national survey. 7 Gen Intern Med 2014;29(9):1226-33.

31. Winkelman TNA, Genao I, Wildeman C, et al. Emergency department and hospital use among adolescents with justice system involvement. Pediatrics 2017;140(5).

32. Krieg C, Hudon C, Chouinard MC, et al. Individual predictors of frequent emergency department use: a scoping review. BMC Health Serv Res 2016;16(1):594.

33. Moe J, Kirkland SW, Rawe E, et al. Effectiveness of interventions to decrease emergency department visits by adult frequent users: a systematic review. Acad Emerg Med 2017;24(1):40-52.

34. Fahmy N, Kouyoumdjian FG, Berkowitz J, et al. Access to primary care for persons recently released from prison. Ann Fam Med 2018;16(6):549-51.

35. Frank JW, Wang EA, Nunez-Smith M, et al. Discrimination based on criminal record and healthcare utilization among men recently released from prison: a descriptive study. Health Fustice 2014;2:6.

36. Kouyoumdjian FG, Lai W, Orkin A, et al. A 25-year-old woman with diabetes in custody. CMA7 2016;188(1718):1249-50.

37. Nolan B, Ackery A. Collaborating with police in the emergency department while maintaining patient confidentiality: how can we improve? CFEM 2015;17 (4):437-42. 